\title{
Protection of L1 nerve roots by pre-relieve tension in parallel endplate osteotomy for severe rigid thoracolumbar spine deformity
}

Hang Liao

Shenzhen University

Houguang Miao

Shenzhen University

Peng Xie

Shenzhen University

Yueyue Wang

Shenzhen University

Ningdao Li

Shenzhen University

Guizhou Zheng

Shenzhen University

Xuedong Li

Shenzhen University

Shixin Du ( D DSX333126@126.com )

Shenzhen University

\section{Research article}

Keywords: Thoracolumbar deformity, Nerve roots injury, L1 nerve roots, Parallel endplate osteotomy

Posted Date: April 14th, 2020

DOI: https://doi.org/10.21203/rs.2.20867/v3

License: (c) (i) This work is licensed under a Creative Commons Attribution 4.0 International License. Read Full License

Version of Record: A version of this preprint was published at BMC Musculoskeletal Disorders on May 15th, 2020. See the published version at https://doi.org/10.1186/s12891-020-03288-0. 


\section{Abstract}

Background: This is a retrospective study of the use of parallel endplate osteotomy (PEO) for correction of severe rigid thoracolumbar spine deformity.

Methods: From July 2016 to January 2019, 12 patients with severe rigid thoracolumbar spine deformity underwent PEO on T12 or L1 vertebrae were studied.

Results: Following PEO at T12 or L1, the mean kyphosis and scoliosis correction rates reached $77.0 \pm$ $8.9 \%$ and $75.5 \pm 8.0 \%$, respectively and the intraoperative estimated blood loss was $1950 \pm 1050 \mathrm{~mL}$, and the mean operative time was $6.98 \pm 4.02 \mathrm{~h}$. The SF-36 scores of physical function, role-physical, bodily pain, general health, vitality, social function, role-emotional and mental health changed from $63 \pm 28,50 \pm$ $25,50 \pm 30,34 \pm 19,53 \pm 28,45 \pm 30,30 \pm 36$ and $54 \pm 18$ at baseline to $83 \pm 18,69 \pm 19,72 \pm 12,66 \pm$ $21,75 \pm 15,72 \pm 22,66 \pm 34$ and $76 \pm 12$ at one year postoperatively , $83 \pm 8,68 \pm 32,83 \pm 17,73 \pm 17,82$ $\pm 18,76 \pm 26,70 \pm 37$ and $88 \pm 12$ at 18 months postoperatively, $86 \pm 6,83 \pm 33,90 \pm 16,81 \pm 16,89 \pm 14$, $88 \pm 25,83 \pm 17$ and $94 \pm 10$ at 24 months postoperatively, respectively $(P<0.01)$. Three patients had symptoms of $L 1$ nerve root injury, as reflected by lower limb weakness and inner thigh numbness on knee extension and hip flexion, which was further confirmed by electromyography.

Conclusions: PEO is easier to operate, and the spinal cord and nerve root are under direct vision and can effectively and safely correct severe rigid thoracolumbar spine deformity with satisfactory clinical results. However, it is important to identify, separate and protect L1 nerve roots during surgery in cases where patients have symptoms of back pain, muscle weakness and leg numbness on the convex side after surgery.

\section{Background}

Severe rigid thoracolumbar spine deformity, a thoracolumbar spinal deformity with a kyphosis or a scoliosis angle of over 80 degrees after bending or traction (flexibility $<25 \%$ ) $^{[1]}$, is comprised of a variety of spinal deformities, such as untreated adolescent idiopathic scoliosis, spinal congenital malformations, spinal hemivertebra malformations, incomplete segmental malformations and deformity caused by ankylosing spondylitis ${ }^{[2]}$. As the disease progresses, the thoracolumbar spine becomes ossified and the patient develops chest and back pain with stiffness. Patients with severe rigid thoracolumbar spinal deformity mostly have respiratory restriction, suffocating breathing and limited cardiac output ${ }^{[3]}$.

For severe rigid deformity, spinal osteotomy is recommended ${ }^{[4]}$. Spinal osteotomy ideally should involve a single surgical approach to decompress nerve roots, correct the deformity and stabilize the spine ${ }^{[5]}$. Due to the pathological characteristics of severe rigid thoracolumbar spine deformity, osteotomy is extremely challenging for spine surgeons, and is accompanied by a high rate of complications, including neurological lesions, blood loss, infection, pseudarthrosis, fixation failure and loss of correction ${ }^{[6]}$. Nerve root injury is a common disastrous problem in osteotomy ${ }^{[7]}$. T12 or L1 are usually taken as the apical 
vertebra for spinal osteotomy ${ }^{[8]}$. Because the canalis vertebralis at T12 and L1 contains the spinal cord, nerve roots and medullary cone, spinal osteotomy at T12 or L1 vertebra is more dangerous than at lower levels ${ }^{[9]}$. As a result, T12 or L1 osteotomy is more likely to injure L1 nerve roots, especially in severely rotated vertebra on the convex side, where L1 nerve roots, unlike T12 nerve roots, could penetrate through the surface of the vertebra, which causes symptoms such as back pain, muscle weakness and leg numbness, thus interfering with daily activities ${ }^{[10]}$. Therefore, it is necessary to reduce the risk of various complications, so as to effectively protect L1 nerve roots.

Our research group used Mimics medical three-dimensional (3D) reconstruction software to reconstruct 3D digital models of various vertebral bodies, and provide optimal osteotomy and fixed segments for the operation. We utilized parallel endplate osteotomy (PEO) to treat severe rigid thoracolumbar spinal deformity and achieved satisfactory clinical results. The PEO technique is preferable to one-stage osteotomy instead of traction before surgery. In particular, we pay special attention to identification, separation, tension reduction and protection of $\mathrm{L} 1$ nerve roots during surgery.

\section{Methods}

\section{Patients}

This retrospective study included 12 patients with severe rigid thoracolumbar spine deformity who underwent PEO at T12 or L1 between July 2016 and January 2019. Deformity was assessed both clinically and radiographically as part of the preoperative planning. Diagnosis of thoracolumbar spine deformity was made by human grid analysis, $X$-rays after bending or traction, 3D CT and 3D printing models. Patient complaints included serious waist deformity, lower back pain and increased lower limb weakness and leg numbness after activity. All patients underwent a one-stage osteotomy instead of preoperative traction. The inclusion criteria: patients with severe rigid thoracolumbar spine deformity who underwent PEO at T12 or L1. The exclusion criteria: patients with spinal cord or nerve root injury or other serious respiratory complications were excluded.

\section{Assessment of deformity}

Using standard Cobb's method on standing lateral radiograph of the whole spine, the global thoracolumbar kyphosis or scoliosis was measured from the upper endplate of $\mathrm{T} 1$ to the lower endplate of L5. Severe rigid spinal deformity was defined as having curve angles more than $80^{\circ}$, with flexibility less than $25 \%$ by X-rays after bending or traction ${ }^{[1]}$, exclusion patients with spinal cord or nerve root injury or have other serious respiratory complications. Radiographic parameters were evaluated, and clinical records were reviewed. The osteotomy location was usually chosen as the vertebra that contributed most to the deformity, according to the apex of the deformity. Such a measurement not only represents the severity of the overall deformity, but also determines the amount of correction to be achieved by spinal osteotomy.

\section{The surgical procedure}


The patient was placed prone over the table, which was in a flat position throughout the operation. The location of the upper and lower end vertebrae was determined by mobile $\mathrm{C}$-arm $\mathrm{X}$-ray imaging before surgery. The vertebral column from the upper to the lower end vertebrae was prepared and draped. A straight vertical midline incision was made over the spinous processes and was extended to the upper and lower end vertebrae. If the deformed vertebra had a rotation, an incision was made on the convex side, deviating approximately $1-2 \mathrm{~cm}$ from the centerline. The paraspinal muscles were dissected subperiosteally from the spinous processes and laminae, and then retracted laterally. After a careful dissection of the area around the facet joints, a large spinal retractor was applied. By spreading the spinal retractor and detachment of muscles around the facet joints, a wider exposure was obtained. The spinal retractor could reduce soft tissue damage and infection, and avoid long-term traction. An intraoperative radiograph with guide pins was obtained for accurate localization of the deformity and determination of the level and area for osteotomy. Pedicle screws were then inserted into the segments from the upper end vertebra to the lower end vertebra using a free-hand technique at all levels planned prior to surgery. The osteotomy site was usually chosen as the vertebra that contributed most to the deformity, according to the apex of the deformity.

Usually the spine was stabilized with a short bent rod in situ adjacent to the resected area to avoid coronal and sagittal plane translation during the reduction maneuver. The first unilateral rod was temporarily fixed on the concavity side bend to maintain spinal stability after PEO. A complete laminectomy and facetectomy was performed to expose the spinal cord. Usually, the spinal cord was located in the concave curve side, sometimes slightly located in the convex curve side. If the spinal cord was located in the convex curve side, greater caution should be exercised because of neurological complications due to high tension of the spinal cord. In some cases, the spinal cord was as tight as a cord with the diameter of only one-third of a normal spinal cord. Any slight maneuver would make the action potentials to decline sharply by over $50 \%$, or even disappear. Timely identification and prompt intervention must be performed, including enlarging the resected area to reduce the abrupt turning tendency of the spinal cord.

In our experience, we removed two levels of nerve roots of the thoracolumbar spinal cord for PEO, if necessary. These procedures allow circum-spinal decompression of the spinal cord. One of the critical pitfalls in this step was the careless mistake of pulling out the preserved spinal nerve roots at the corresponding level. This was quite dangerous for the spinal cord, which was already compressed at the apex of the angular kyphotic deformity, because pulling out the nerve root increased the pressure of the spinal cord at the apex. When the initial PEO was carried out, we did not pay special attention to the L1 nerve roots. Due to position variation, we made the careless mistake of regarding $L 1$ as $T 12$ nerve roots and damaged L1, which was confirmed by lower limb EMG after surgery. Thereafter, we attempted to use a nerve stripper to separate and release the tension of the L1 nerve roots under somatosensory-evoked potential (SEP) and motor-evoked potential (MEP) monitoring, ultimately leaving the L1 nerve roots slack and floating in the gap. 
For PEO, the pedicle of the vertebral arch, $2 / 3$ of the posterior vertebra, the bilateral walls of the vertebra and the posterior wall of the vertebra ( $5 \mathrm{~mm}$ to endplate) were carefully removed using an osteotome, curette, rongeur and ultrasonic osteotome (Figure 1). The parallel endplate osteotomy area had two situations: a single vertebral osteotomy if the angle of the curve was less than $90^{\circ}$, or a multiple vertebral osteotomy if the angle of the curve was greater than $90^{\circ}$. If the spinal cord was compressed at the apex of the angular deformity, the lesion compressing the spinal cord was also drilled out using an L-shaped bone separator under direct vision from the lateral direction. A thin stripper was used to confirm whether the soft tissue, such as the posterior longitudinal ligament, attached to the dural sac was soft enough.

The osteotomy was performed carefully to avoid over-penetration of the anterior vertebral body cortex or anterior intervertebral disc for the purpose of preventing injury to the major vessels in front of the vertebral body. Then, we inserted another precontoured correction rod on the convex side to exchange the rods, 30 degrees per correction. It was important in this step to keep an adequate compression force on the concave rod while its adjunct screws on the cephalic side were slightly released until the concave rod and screws were tightened one by one. In situ rod bending on the concave side should never be performed because it is very dangerous procedure to the naked spinal cord, and applying too much torsion to the pedicle screws could easily cause screw loosening and rod bender stick out and injure the spinal cord. After repeated compressions and shuttling segmental transient rods, finally, we placed the terminal fixation rods after main correction was achieved. Then, segmental derotation, compression, and distraction on the secondary curves were performed to achieve final correction. During the entire correction procedure, the dural sac was closely observed to avoid migration in any direction, and tension of the spinal cord was assessed by observation and frequent palpation. Adequate and quick adjustments were needed to ensure that spinal cord tension did not exceed the initial state under distraction, and to prevent excessive kinking of the dural sac after spinal shortening. Kawahara et al. confirmed that the spine that was shortened within one-third of the height of the vertebrae would not lead to a functional change of the spinal cord ${ }^{[11]}$. During osteotomy, we had a maximum spinal shortening of 5 centimeters, there were no warning signs by SEP and MEP. After completion of resection and deformity correction, any residual gap was filled with resected vertebral body bone morsels. Finally, we checked that the spinal cord was thoroughly smooth. We gave patients an autologous blood transfusion that was recycled, or allogeneic blood transfusion if the volume of bleeding was high.

\section{Intraoperative monitoring technique and postoperative follow-up}

We monitored the somatosensory-evoked potential (SEP) and motor-evoked potential (MEP) to effectively monitor the spinal cord and nerve roots under the supervision of an experienced neurophysiologic physician throughout the PEO procedure, and an additional wake-up test was performed after finishing the correction step at the end of the surgery to ensure the neurological status. Intraoperative and postoperative complications were recorded. For patients with L1 nerve roots injury, continuous electromyography (EMG) monitoring was necessary. In an attempt to validate these patients' clinical outcome, 12 patients were also asked to respond to the SF-36 quality of life questionnaire via telephone interview after a year of follow-up. 


\section{Results}

In total, 12 severe rigid thoracolumbarspine deformity patients received a PEO at T12 or L1. The threedimensional model provided accurate diagnostic and better surgical options. The kyphosis and scoliosis correction rates reached $77.0 \pm 8.9 \%$ and $75.5 \pm 8.0 \%$, respectively. The mean intraoperative estimated blood loss was $1950 \pm 1050 \mathrm{~mL}$ and the mean operative time was $6.98 \pm 4.02 \mathrm{~h}$. Osteotomies were all performed at T12 or L1. Three patients had typical symptoms of L1 nerve root injury. Specifically, the lower limb exhibited weakness on knee extension and hip flexion, and the inner thigh felt numb (Table 1). Table 2 and 3 shows SF-36 scores of the patients at baseline, one year, 18 months and 24 months postoperatively, respectively. The SF-36 scores of physical function, role-physical, bodily pain, general health, vitality, social function, role-emotional and mental health changed from $63 \pm 28,50 \pm 25,50 \pm 30$, $34 \pm 19,53 \pm 28,45 \pm 30,30 \pm 36$ and $54 \pm 18$ at baseline to $83 \pm 18,69 \pm 19,72 \pm 12,66 \pm 21,75 \pm 15,72$ $\pm 22,66 \pm 34$ and $76 \pm 12$ at one year postoperatively , $83 \pm 8,68 \pm 32,83 \pm 17,73 \pm 17,82 \pm 18,76 \pm 26$, $70 \pm 37$ and $88 \pm 12$ at 18 months postoperatively, $86 \pm 6,83 \pm 33,90 \pm 16,81 \pm 16,89 \pm 14,88 \pm 25,83 \pm$ 17 and $94 \pm 10$ at 24 months postoperatively, respectively $(P<0.01$, Student's $t$ test), indicating that the quality of life of the patients improved significantly after PEO.

However, although the clinical effect of the PEO technique was obvious, complications were unavoidable. L1 nerve roots injury occurred in 3 patients, with abnormal SEP and MEP waveforms during the operation that was confirmed by lower limb EMG after surgery. The symptoms of L1 nerve root injury were significantly improved by pharmacotherapy with mannitol and methylprednisolone and nutritional neurotherapy. We could see that L1 nerve root function was obviously improved by continuously monitoring EMG of both lower limbs. Meanwhile, 1 case developed hemopneumothorax, which was effectively repaired without any leakage, and a closed thoracic drainage tube was placed post operation. One patient experienced paralytic ileus which improved after gastric decompression, promoting intestinal motility and symptomatic medical treatment. At one year follow up, we did not observe any other complications, such as dura laceration, superficial infection, nonunion/rod breakage, distal screw loosening and adjacent segment kyphosis (Table 4).

\section{Data Analysis}

A Student's t test was used to evaluate the differences after surgery. Statistical significance was set at a value of $P<0.01$. Data are displayed as mean \pm SD unless otherwise indicated.

\section{Case 1}

A 33-year old housewife had waist deformity for 18 years that worsened over the last year. The spine deformity was serious. In the flexion test, the left side of the waist was raised $10 \mathrm{~cm}$, the muscle strength of both lower limbs was grade $\mathrm{V}$, and the patient had normal sensation. The preoperative diagnosis was severe rigid thoracolumbar deformity; kyphosis Cobb $85^{\circ}$ and scoliosis Cobb $67^{\circ}$ was determined by X-ray after bending (Figure 2A). Osteotomy was performed at T11 and T12, and the upper and lower end vertebrae were T8 and L4 (Figure 2B). Due to position variation, we mistakenly identified L1 as the T12 
nerve root, and damaged the L1 nerve root on the convex side of the side bend with abnormal waveforms by SEP and MEP during the operation (Figure 2D). Despite postoperative kyphosis and scoliosis correction to Cobb $12^{\circ}$ and $15^{\circ}$ (Figure $2 \mathrm{C}$ ), knee extension and hip flexion of the left lower limb were

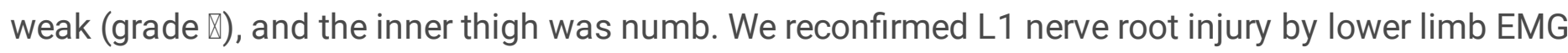
after surgery. After pharmacotherapy with mannitol and methylprednisolone and nutritional neurotherapy, the muscle strength of the left lower limb recovered to grade IV, and numbness was relieved before the patient was discharged from the hospital. At one year follow-up after surgery, the patient still had left lower limb weakness, which had an impact on daily life.

\section{Case 2}

A 21-year old delivery man had waist deformity for 10 years that was worsened over the past 4 years. In the flexion test, the left waist was raised $8 \mathrm{~cm}$, the muscle strength of both lower limbs was grade $\mathrm{V}$, and there was no numbness. The preoperative diagnosis was severe rigid thoracolumbar deformity; kyphosis Cobb $90^{\circ}$ and scoliosis Cobb $130^{\circ}$ was determined by X-rays after bending (Figure $2 \mathrm{~A}$ ). Osteotomy was performed at T12 and L1, and the upper and lower end vertebrae were T5 and L5 (Figure 2B). Due to high tension, we mistakenly damaged the L1 nerve root on the convex side with abnormal waveforms by SEP and MEP during the operation (Figure 2D). Despite postoperative kyphosis and scoliosis correction to Cobb $25^{\circ}$ and $40^{\circ}$ (Figure 2C), knee extension and hip flexion of the left lower limb were grade II, and the inner thigh was numb. After surgery, L1 nerve root injury was confirmed by EMG. After a period of therapy, the muscle strength of the left lower limb recovered to grade IV, and numbness was markedly reduced before the patient was discharged from the hospital. At one year follow-up, the patient could not go up the stairs smoothly, which had an impact on his work.

\section{Case 3}

A 22-year old male had waist deformity for 8 years that was worsened over the preceding two years. In the flexion test, the left side of the waist was raised $14 \mathrm{~cm}$, and the muscle strength of both lower limbs was grade $\mathrm{V}$, indicating serious spine deformity (Figure $3 \mathrm{~A}$ ). Preoperative diagnosis was severe rigid thoracolumbar kyphosis, with a kyphosis Cobb angle of $102^{\circ}$ and a scoliosis Cobb angle of $118^{\circ}$ as judged by X-ray after bending (Figure 3B, 3C and 3D). Osteotomy was performed at L1 and L2, and the upper and lower end vertebrae were T8 and S1. During the operation, we observed that the L1 nerve roots on the convex side of the scoliosis were pulling tension and easily damaged (Figure 3E). We tried to use nerve strippers to separate and protect the L1 nerve root while maintaining normal waveforms by SEP and MEP during the operation (Figure 3F). The L1 nerve roots were slack and floating in the gap (Figure $3 \mathrm{E}$ ). Kyphosis and scoliosis were corrected to Cobb $32^{\circ}$ and $35^{\circ}$, respectively, postoperatively (Figure $3 \mathrm{G}$ ) and the patient had no symptoms of nerve root injury.

\section{Discussion}

Surgical intervention is the only effective method for correction of severe rigid thoracolumbar spine deformity, and can restore the sagittal balance of the spine and the horizontal gaze, improve respiratory 
function, relieve pain and enhance quality of life ${ }^{[12]}$. Current surgical methods include pedicular subtraction osteotomy (PSO) and vertebral column resection (VCR) ${ }^{[12]}$. PSO is described as a vertebral wedge osteotomy for correction of spine deformity. It has the advantage of obtaining correction through three columns, from the posterior approach, without lengthening the anterior column, thereby maximizing healing potential while avoiding stretching the major vessels and viscera anterior to the spine ${ }^{[13]}$. The mean estimated blood loss in PSO procedures has been reported in the literature to be from $1400 \mathrm{~mL}$ to $2600 \mathrm{~mL}^{[14]}$, and the mean operative time was $9.1 \mathrm{~h}^{[15]}$. The VCR technique can achieve a $360^{\circ}$ osteotomy of the entire spine and have yielded satisfactory results ${ }^{[16]}$; in this technique, the intraoperative estimated blood loss is generally around $3000-5000 \mathrm{~mL}$, and the mean operative time is $9.3 \mathrm{~h}^{[17]}$. For spine deformity, PSO and VCR are classic techniques and can achieve satisfactory results. Meanwhile, the PEO technique provides a new alternative treatment for spinal deformities, with an estimated blood loss of $1950 \pm 1050 \mathrm{~mL}$ and a mean operative time of $6.98 \pm 4.02 \mathrm{~h}$. PEO includes the pedicle of the vertebral arch, $2 / 3$ of the posterior vertebra, the bilateral walls of the vertebra and the posterior wall of the vertebra ( $5 \mathrm{~mm}$ to the endplate), which does not require through pedicular osteotomy (like PSO) and resection of the intervertebral disc above and below the osteotomy site (like VCR). Moreover, the endplate as a mark in PEO is easy to identify which has a large operating space, and is especially suitable for pedicle deformity or agenesis which is unrecognizable, which is easier to operate for orthopedic surgeons. With bone-bone fusion, we can achieve a higher spinal fusion rate and better spine stability, in order to reduce the risk of rod breakage. Despite the low risk of rod breakage, at one year follow-up, we still have a case of rod breakage who underwent PEO not at T12 or L1. Due to pregnancy after surgery, the increased force on the spine may lead to rod breakage.

In addition, Valone et al. observed that lumbar nerve root weakness or injury can be variously attributed to operative manipulation or decompression and occurs in up to $30 \%$ of spinal deformity cases ${ }^{[18]}$. Compressive injury may also occur during manipulation of the spinal column, especially after a 3-column osteotomy, whereby osseous or ligamentous structures come to rest on the nerve roots in proximity to the osteotomy ${ }^{[19]}$. Over-pulling nerve roots often causes degeneration, leading to lower limb weakness and numbness. Moreover, nerve root tension often leads to position variation. As a result, the slim nerve root is often located on the lateral side of the scoliosis vertebrae, where it is easily damaged. Sometimes, L1 nerve roots are more likely to appear in the position of T12. In our experience, retention of the T12 nerve root is not required, due to its relatively low influence on lower limb function. However, we once mistook L1 for the T12 nerve root and damaged it. After osteotomy, the L1 nerve roots are easily pinched in the osteotomy space. In general, for T12 or L1 osteotomy, predicting and preventing L1 nerve root injury are paramount in improving postoperative health-related quality of life and function.

Therefore, we reconstruct a 3D digital model of all vertebral bodies to simulate the spinal cord changes in severe rigid spinal deformity after osteotomy correction. It can provide more reasonable solutions for ideal correction degrees, thoracic reshaping, estimation of the spinal cord, post-somatic correction and nerve root safety. Severe rigid spinal deformity still follows the traditional method of preoperative traction. Traction as a form of spinal orthopedics has been widely used, and plays an important auxiliary 
role in preoperative correction and second-stage osteotomy ${ }^{[20]}$. Meanwhile, traditional traction can cause additional pain to the patient and is more prone to serious complications, such as cranial nerve injury, cervical spondylosis, loosening and infection ${ }^{[21]}$. Our team used the PEO technique for one-stage osteotomy, which does not need traction before surgery, dramatically reducing patient suffering, treatment costs and various complications.

In some cases, the L1 nerve roots are pulled tight, causing position variation, and can adhere to surrounding tissues. L1 nerve root injury often causes lower limb weakness and numbness. As a result, we used a nerve stripper to separate, pre-relieve tension and protect L1 nerve roots, while monitoring the process by the SEP and MEP, in order to reduce the risk of nerve root damage. The osteotomy angle can reach $110^{\circ}-140^{\circ}$, basically satisfying any angle requirements for correction of spinal deformity. The correction rate can reach $70 \%-86 \%$, which is better than the traditional correction rate of $55 \%-60 \%$ [22] During osteotomy, we had a maximum spinal shortening of 5 centimeters, but we did not worry about the excessive ruga of the dural sac. Because there were no monitoring warning signs by SEP and MEP, after osteotomy, the postoperative bone-bone fusion rate was significantly improved with intervertebral bone graft. Short-term complications after surgery, such as L1 nerve root injury, paralytic ileus and hemithorax all improved or were cured by appropriate treatment. At one year follow-up after surgery, it is obvious from the SF-36 scores that all patients achieved better clinical results and with no other complications. In addition, we are aware of the importance of protecting L1 nerve roots.

\section{Conclusions}

We performed parallel endplate osteotomy (PEO) directly on the vertebral body (5 $\mathrm{mm}$ to the endplate), and $1 / 3$ of the vertebral body as a mechanical orthopedic hinge. The endplate as a mark in PEO is easy to identify which has a large operating space, and is especially suitable for pedicle deformity or agenesis which is unrecognizable, with bone-bone fusion, which is easier to operate, spinal cord and nerve root under direct vision and can effectively and safely correct severe rigid thoracolumbar spine deformity with better clinical results. Nerve roots injury is a commonly disastrous problem in osteotomy. As a result, due to position variation, T12 or L1 osteotomy is more likely to damage the L1 nerve roots, which are not easy to identify, especially in the severely rotated vertebra on the convex side, and, unlike T12 nerve roots, are usually approached through the surface of the vertebra which causes symptoms such as back pain, muscle weakness and leg numbness, thus interfering with daily activities. Therefore, it is necessary to reduce the risk of various complications, so as to effectively protect L1 nerve roots.

\section{Abbreviations}

Parallel endplate osteotomy (PEO), somatosensory-evoked potential (SEP), motor-evoked potential (MEP), electromyography (EMG), pedicular subtraction osteotomy (PSO) and vertebral column resection (VCR).

\section{Declarations}




\section{Ethics approval and consent to participate}

The study protocol has been approved by the Clinical Research Ethics Committee of the Shenzhen University on May 10th, 2016 and has been registered. All patients signed an informed consent form.

\section{Consent to publish}

Written consent was provided for images of the patients and techniques, clinical details and identifying information such as age, profession and gender to be included and published.

\section{Availability of data and materials}

All data generated or analysed during this study are included in this published article and its supplementary information files.

\section{Competing interests}

The authors declare that they have no competing interests.

\section{Funding}

The study was supported by Science and Technology Research and Development Foundation of Shenzhen (JCYJ20160429172357751). SXD as the funder participated in drafting the manuscript, in designing the protocol and provides the original idea of the work.

\section{Authors' contributions}

$\mathrm{HL}$ and SXD participated in drafting the manuscript, in designing the protocol and provides the original idea of the work. HGM, participated in drafting the manuscript and in designing the protocol. PX and YYW participated in revising the manuscript critically and in designing statistical analysis. XDL participated in revising the manuscript critically with reference to the methods to evaluate variables. NDL and GZZ, participated in revising the manuscript critically with reference to the treatment technics to be studied. All authors have read and approved the final manuscript and agreed to be accountable for all aspects of the work.

\section{Acknowledgements}

Not applicable.

\section{Authors' Information}

From the Department of Orthopedics, The 3rd Affiliated Hospital of Shenzhen University, Shenzhen, China. 
*Address correspondence and reprint requests to Shixin Du, MD, PhD or Xuedong Li, MD, PhD, Department of Orthopedics, The 3rd Affiliated Hospital of Shenzhen University, Shenzhen 518000, PR China; Email: DSX333126@126.com or xd1622@sina.com.

\section{References}

1. Hamzaoglu A, Alanay A, Ozturk C, Sarier M, Karadereler S, Ganiyusufoglu K (2011) Posterior vertebral column resection inseverespinal deformities:a total of 102 cases. Spine 36(5):E340-4.

2. Ji ML, Qian BP, Qiu Y, Wang B, Zhu ZZ, Yu Y (2013) Change of aortic length after closing-opening wedge osteotomy for patients with ankylosing spondylitis with thoracolumbar kyphosis: a computed tomographic study. Spine38(22):1361-7.

3. Zeng Y, Chen Z, Qiang QI , Guo Z, Weishi LI, Sun C (2012) Clinical and radiographic evaluation of posterior surgical correction for the treatment of moderate to severe post-tuberculosis kyphosis in 36 cases with a minimum 2-year follow-up. J Neurosurg Spine 16(4):351-8.

4. Cahill PJ, Wang W, Asghar J, Booker R, Betz RR, Ramsey C (2012) The use of a transition rod may prevent proximal junctional kyphosis in the thoracic spine after scoliosis surgery: a finite element analysis. Spine 37(12):687-95.

5. Bridwell KH (2006) Decision making regarding Smith-Petersen vs. pedicle subtraction osteotomy vs. vertebral column resection for spinal deformity. Spine 31(Suppl 1):171-8.

6. Zeng Y, Qu X, Chen Z, Yang X, Guo Z, Qi Q (2016) Posterior corrective surgery for moderate to severe focal kyphosis in the thoracolumbar spine: 57 cases with minimum 3 years follow-up. Eur Spine $J$ 26:1-9.

7. Coe JD, Arlet V, Donaldson W, Berven S, Hanson DS, Mudiyam R (2006) Complications in spinal fusion for adolescent idiopathic scoliosis in the new millennium. A report of the Scoliosis Research Society Morbidity and Mortality Committee. Spine 31(3):345-9.

8. Xu H, Zhang Y, Zhao Y, Zhang X, Xiao S, Wang Y (2015) Radiological and clinical outcomes comparison between single and two level pedicle subtraction osteotomies in correcting ankylosing spondylitis kyphosis. Spine 15(2):290-7.

9. Zheng GQ, Zhang YG, Wang Y, Huang P, Cui G (2014) Two-level spinal osteotomy for severe thoracolumbar kyphosis in ankylosing spondylitis. Experience with 48 patients. Spine 39(13):10558.

10. Wu W, Liang J, Ru N (2016) Microstructural changes in compressed nerve roots are consistent with clinical symptoms and symptom duration in patients with lumbar disc h Spine 41(11):E661-6.

11. Kawahara N, Tomita K, Kobayashi T, Abdel-Wanis ME, Murakami H, Akamaru T (2005) Influence of acute shortening on the spinal cord: an experimental study. Spine 30(5): S91-

12. Loon PV, Stralen GV, Loon CV, Susante, JV (2006) A pedicle subtraction osteotomy as an adjunctive tool in the surgical treatment of a rigid thoracolumbar hyperkyphosis; a preliminary report. Spine 6(2):195-200. 
13. Park JH, Hyun SJ, Kim KJ, Jahng TA (2017) Comparative study between pedicle subtraction osteotomy (PSO) and closing-opening wedge osteotomy (fish-mouth PSO) for sagittal plane deformity c Spine 42:E899-905.

14. Lamartina C, Casero G (2011) Bleeding control in pedicle subtraction osteotomy. Eur Spine J 20(12):2284-85.

15. Huang JH, Yang WZ, Shen C, Chang MS, Li H, Luo ZJ (2015) Surgical treatment of congenital scoliosis associated with tethered cord by thoracic spine-shortening osteotomy without cord detethering.Spine 40(20):

16. Kadoury S, Labelle H (2012) Classification of three-dimensional thoracic deformities in adolescent idiopathic scoliosis from a multivariate analysis. Eur Spine J 21(1):40-9.

17. Yang C, Zheng Z, Liu H, Jian W, Yong J, Kim C (2016) Posterior vertebral column resection in spinal deformity: a systematic review. Eur Spine J 25(8):2368-75.

18. Rd VF, Lyon R, Lieberman J, Burch, S (2014) Efficacy of transcranial motor evoked potentials, mechanically elicited electromyography and evoked electromyography to assess nerve root function during sustained compression in a porcine model. Spine 39(17):989-93.

19. Wang MY, Berven SH (2007) Lumbar pedicle subtraction osteotomy. Neurosurgery 60(2):171-6.

20. Sink EL, Karol LA, Sanders J, Birch JG, Johnston CE, Herring JA (2001) Efficacy of perioperative halogravity traction in the treatment of severe scoliosis in children. J Pediatr Orthop 21(4):519-24.

21. Rinella A, Lenke L, Whitaker C, Kim Y, Park SS, Peelle, M (2005) Perioperative halo-gravity traction in the treatment of severe scoliosis and kyphosis. Spine 30(4):475-82.

22. Cui G, Wang Y, Kao TH, Zhang Y, Liu Z, Liu B (2012) Application of intraoperative computed tomography with or without navigation system in surgical correction of spinal deformity: a preliminary result of 59 consecutive human cases. Spine 37(10):891-900.

\section{Tables}

Table 1. Summarized data of patients.

Table 2. Comparison of SF-36 scores before and one year after surgery. 


\begin{tabular}{|c|c|c|c|c|c|c|c|c|c|c|c|}
\hline \multirow[t]{2}{*}{$\begin{array}{l}\text { Patient } \\
\text { No. }\end{array}$} & \multirow[t]{2}{*}{$\begin{array}{l}\text { Age/ } \\
\text { Sex }\end{array}$} & \multirow[t]{2}{*}{ Etiology } & \multicolumn{2}{|c|}{$\begin{array}{l}\text { Kyphosis } \\
\text { Cobb } \\
\text { (degrees) }\end{array}$} & \multicolumn{2}{|c|}{$\begin{array}{l}\text { Scoliosis } \\
\text { Cobb } \\
\text { (degrees) }\end{array}$} & \multirow[t]{2}{*}{$\begin{array}{l}\text { Osteotomy } \\
\text { segments }\end{array}$} & \multirow{2}{*}{$\begin{array}{l}\text { Upper } \\
\text { and } \\
\text { lower } \\
\text { end } \\
\text { vertebra }\end{array}$} & \multirow[t]{2}{*}{$\begin{array}{l}\text { Bleeding } \\
(\mathrm{mL})\end{array}$} & \multirow{2}{*}{$\begin{array}{l}\text { L1 } \\
\text { nerve } \\
\text { roots } \\
\text { injury }\end{array}$} & \multirow[t]{2}{*}{$\begin{array}{l}\text { Operative } \\
\text { time } \\
\text { (hours) }\end{array}$} \\
\hline & & & $\begin{array}{l}\text { Pre-- } \\
\text { Post }\end{array}$ & & $\begin{array}{l}\text { Pre } \\
\text { Pos }\end{array}$ & & & & & & \\
\hline 1 & $33 / \mathrm{F}$ & Idiopathic & 85 & 12 & 67 & 15 & T11/T12 & T8-L4 & 1800 & YES & 5.6 \\
\hline 2 & $21 / \mathrm{M}$ & Idiopathic & $\begin{array}{l}90 \\
25\end{array}$ & & $\begin{array}{c}130 \\
40\end{array}$ & & T12/L1 & T5-L5 & 3000 & YES & 11 \\
\hline 3 & $25 / F$ & Congenital & $\begin{array}{c}112 \\
20\end{array}$ & & 98 & 18 & $\mathrm{~T} 12 / \mathrm{L} 1$ & T8-L5 & 1500 & NO & 5.8 \\
\hline 4 & $8 / \mathrm{M}$ & Tuberculosis & 98 & 16 & - & - & $\mathrm{T} 10 / \mathrm{T} 11 / \mathrm{T} 12$ & T5-L4 & 1000 & YES & 6 \\
\hline 5 & $22 / \mathrm{M}$ & Idiopathic & 102 & 32 & $\begin{array}{c}118 \\
35\end{array}$ & & L1/L2 & T8-S1 & 3000 & NO & 5.5 \\
\hline 6 & $10 / F$ & Congenital & $\begin{array}{l}90 \\
22\end{array}$ & & $\begin{array}{l}78 \\
16\end{array}$ & & $\mathrm{~T} 11 / \mathrm{T} 12$ & T6-L3 & 1500 & NO & 5 \\
\hline 7 & $15 / \mathrm{M}$ & Idiopathic & $\begin{array}{c}108 \\
24\end{array}$ & & $\begin{array}{c}131 \\
35\end{array}$ & & T9/T11/T12 & T4-L5 & 2600 & NO & 9 \\
\hline 8 & $24 / F$ & Congenital & 100 & 15 & 85 & 14 & T12/L1 & T9-L5 & 1800 & NO & 6.3 \\
\hline 9 & $16 / \mathrm{M}$ & Congenital & $\begin{array}{c}148 \\
44\end{array}$ & & - & - & T12/L1 & T5-L4 & 2000 & NO & 10 \\
\hline 10 & $20 / F$ & Congenital & $\begin{array}{c}166 \\
46\end{array}$ & & - & - & $\mathrm{T} 10 / \mathrm{T} 11 / \mathrm{T} 12$ & T5-L5 & 1700 & NO & 7 \\
\hline 11 & $38 / F$ & Idiopathic & $\begin{array}{l}85 \\
25\end{array}$ & & $\begin{array}{l}63 \\
15\end{array}$ & & $\mathrm{~T} 12 / \mathrm{L} 1$ & T9-L4 & 2500 & NO & 5.5 \\
\hline 12 & $32 / \mathrm{M}$ & Congenital & $\begin{array}{c}100 \\
20\end{array}$ & & $\begin{array}{l}54 \\
17\end{array}$ & & T12 & T8-L4 & 1000 & NO & 7 \\
\hline
\end{tabular}




\begin{tabular}{|c|c|c|c|c|c|c|c|c|c|c|c|c|c|c|c|c|}
\hline \multirow{2}{*}{$\begin{array}{l}\text { Patient } \\
\text { No. }\end{array}$} & \multicolumn{2}{|c|}{$\begin{array}{l}\text { Physical } \\
\text { Function }\end{array}$} & \multirow{2}{*}{\multicolumn{2}{|c|}{$\begin{array}{l}\text { Role-PhysicalPre } \\
\text { Post }\end{array}$}} & \multirow{2}{*}{\multicolumn{2}{|c|}{$\begin{array}{l}\text { Bodily } \\
\text { Pain } \\
\text { Pre } \\
\text { Post }\end{array}$}} & \multicolumn{2}{|c|}{$\begin{array}{l}\text { General } \\
\text { Health }\end{array}$} & \multirow{2}{*}{\multicolumn{2}{|c|}{$\begin{array}{l}\text { Vitality } \\
\text { Pre } \\
\text { Post }\end{array}$}} & \multicolumn{2}{|c|}{$\begin{array}{l}\text { Sociall } \\
\text { Function }\end{array}$} & \multicolumn{2}{|c|}{$\begin{array}{l}\text { Role- } \\
\text { Emotional }\end{array}$} & \multicolumn{2}{|c|}{$\begin{array}{l}\text { Mental } \\
\text { Health }\end{array}$} \\
\hline & & Post & & & & & Pre & Post & & & Pre & Post & Pre & Post & Pre & Post \\
\hline $\begin{array}{l}1 \\
(33 / F)\end{array}$ & 80 & 85 & 75 & 75 & 62 & 84 & 30 & 45 & 65 & 80 & 50 & 75 & 33 & 66 & 52 & 76 \\
\hline $\begin{array}{l}2 \\
(22 / M)\end{array}$ & 40 & 80 & 25 & 50 & 41 & 62 & 20 & 70 & 55 & 70 & 50 & 75 & 0 & 33 & 52 & 72 \\
\hline $\begin{array}{l}3 \\
(25 / F)\end{array}$ & 75 & 85 & 50 & 75 & 51 & 62 & 25 & 55 & 50 & 75 & 75 & 75 & 66 & 100 & 40 & 84 \\
\hline $\begin{array}{l}4 \\
(33 / F)\end{array}$ & 80 & 90 & 75 & 75 & 74 & 80 & 45 & 65 & 75 & 85 & 50 & 75 & 66 & 100 & 72 & 84 \\
\hline $\begin{array}{l}5 \\
(21 / M)\end{array}$ & 90 & 85 & 75 & 75 & 74 & 80 & 45 & 65 & 80 & 90 & 25 & 75 & 33 & 66 & 68 & 80 \\
\hline $\begin{array}{l}6 \\
(10 / F)\end{array}$ & 50 & 75 & 25 & 75 & 22 & 62 & 20 & 70 & 40 & 65 & 25 & 50 & 33 & 66 & 48 & 76 \\
\hline $\begin{array}{l}7 \\
(15 / M)\end{array}$ & 35 & 65 & 25 & 50 & 20 & 62 & 25 & 65 & 25 & 60 & 38 & 63 & 0 & 33 & 52 & 68 \\
\hline $\begin{array}{l}8 \\
(24 / F)\end{array}$ & 45 & 85 & 25 & 50 & 22 & 74 & 15 & 60 & 45 & 70 & 50 & 75 & 0 & 33 & 36 & 64 \\
\hline $\begin{array}{l}9 \\
(16 / M)\end{array}$ & 55 & 75 & 50 & 75 & 32 & 74 & 40 & 75 & 25 & 65 & 50 & 63 & 0 & 66 & 48 & 72 \\
\hline $\begin{array}{l}10 \\
(20 / F)\end{array}$ & 50 & 85 & 50 & 75 & 40 & 82 & 50 & 85 & 40 & 75 & 50 & 88 & 33 & 66 & 56 & 84 \\
\hline $\begin{array}{l}11 \\
(38 / F)\end{array}$ & 85 & 90 & 75 & 75 & 51 & 62 & 45 & 70 & 65 & 80 & 25 & 75 & 33 & 66 & 52 & 76 \\
\hline $\begin{array}{l}12 \\
(32 / M)\end{array}$ & 75 & 90 & 50 & 75 & 74 & 84 & 45 & 65 & 75 & 85 & 50 & 75 & 66 & 100 & 72 & 80 \\
\hline
\end{tabular}

Table 3. The follow-up SF-36 scores 18 (a) and 24 (b) months after surgery. 


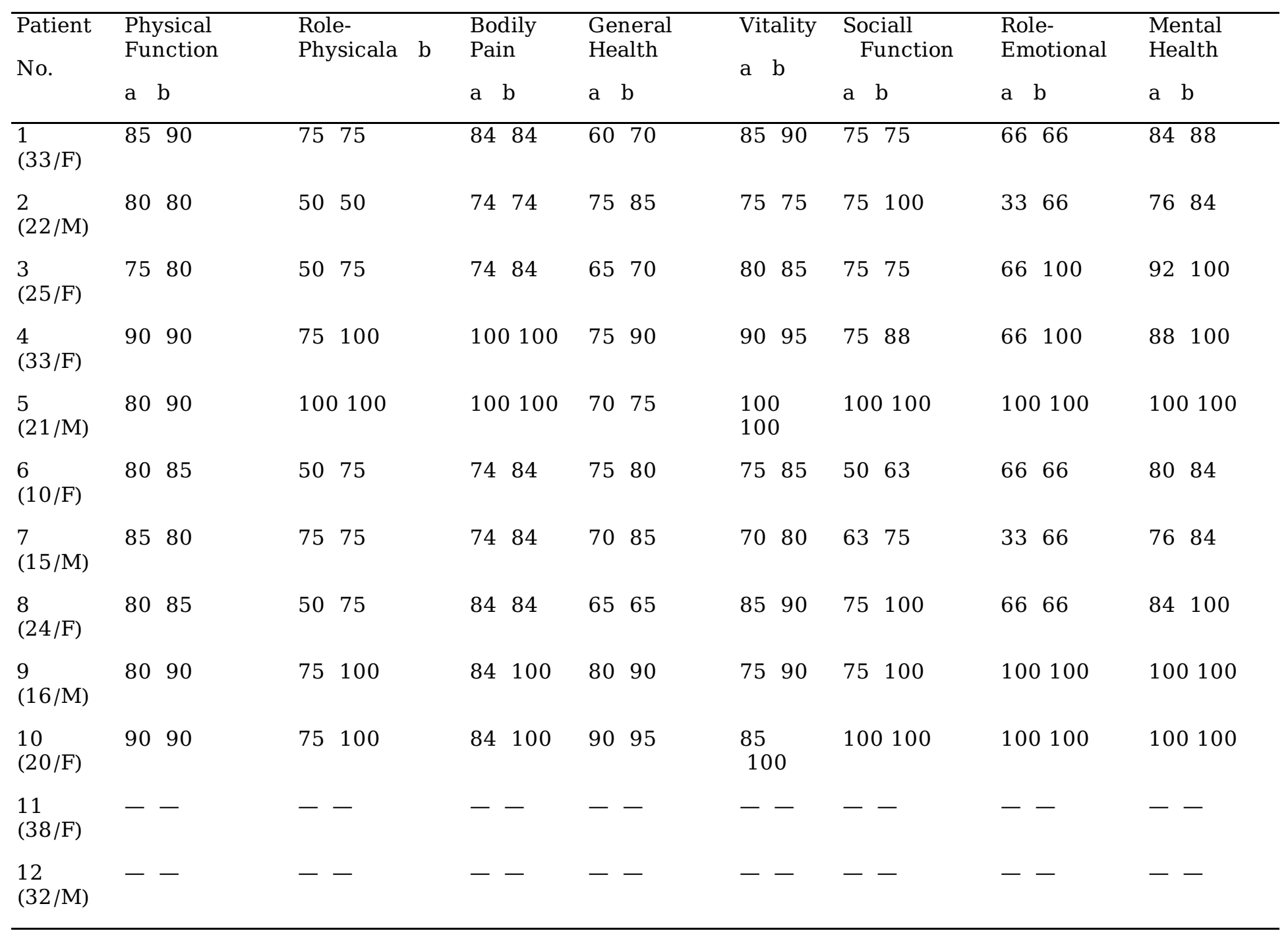

Table 4. Complications in the study patients

\begin{tabular}{ll}
\hline Complication & Patients $(\mathrm{n}=12)$ \\
\hline Dura laceration & 0 \\
L1 nerve root injury & 3 \\
Paralytic ileus & 1 \\
Hemothorax & 1 \\
Superficial infection & 0 \\
Nonunion/rod broken & 0 \\
Distal screw loosening & 0 \\
Adjacent segment kyphosis & 0 \\
\hline
\end{tabular}


Figures

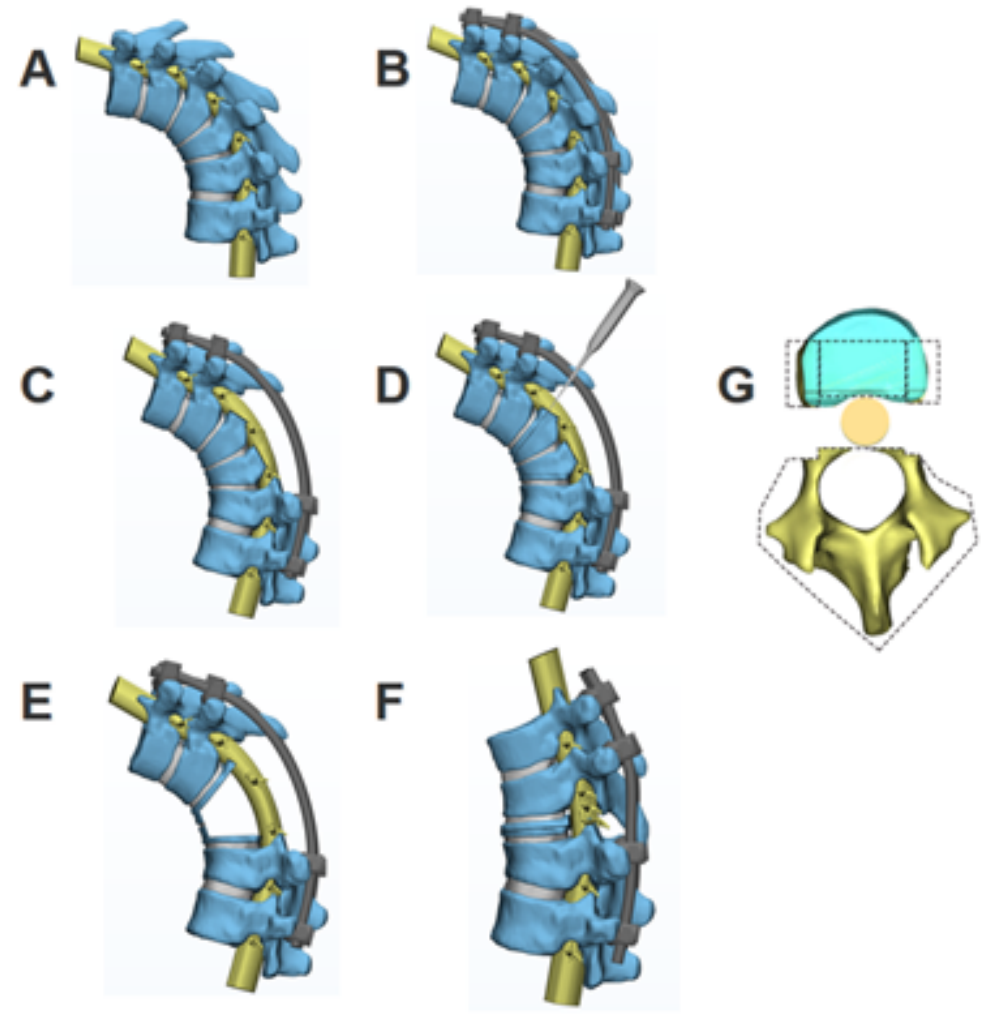

Figure 1

( $A, B, C, D, E$ and $F$ ) The three-dimensional demonstration of parallel endplate osteotomy (PEO). (G) Osteotomy range includes pedicle of the vertebral arch, $2 / 3$ posterior vertebra, bilateral walls of the vertebra and the posterior wall of the vertebra. 


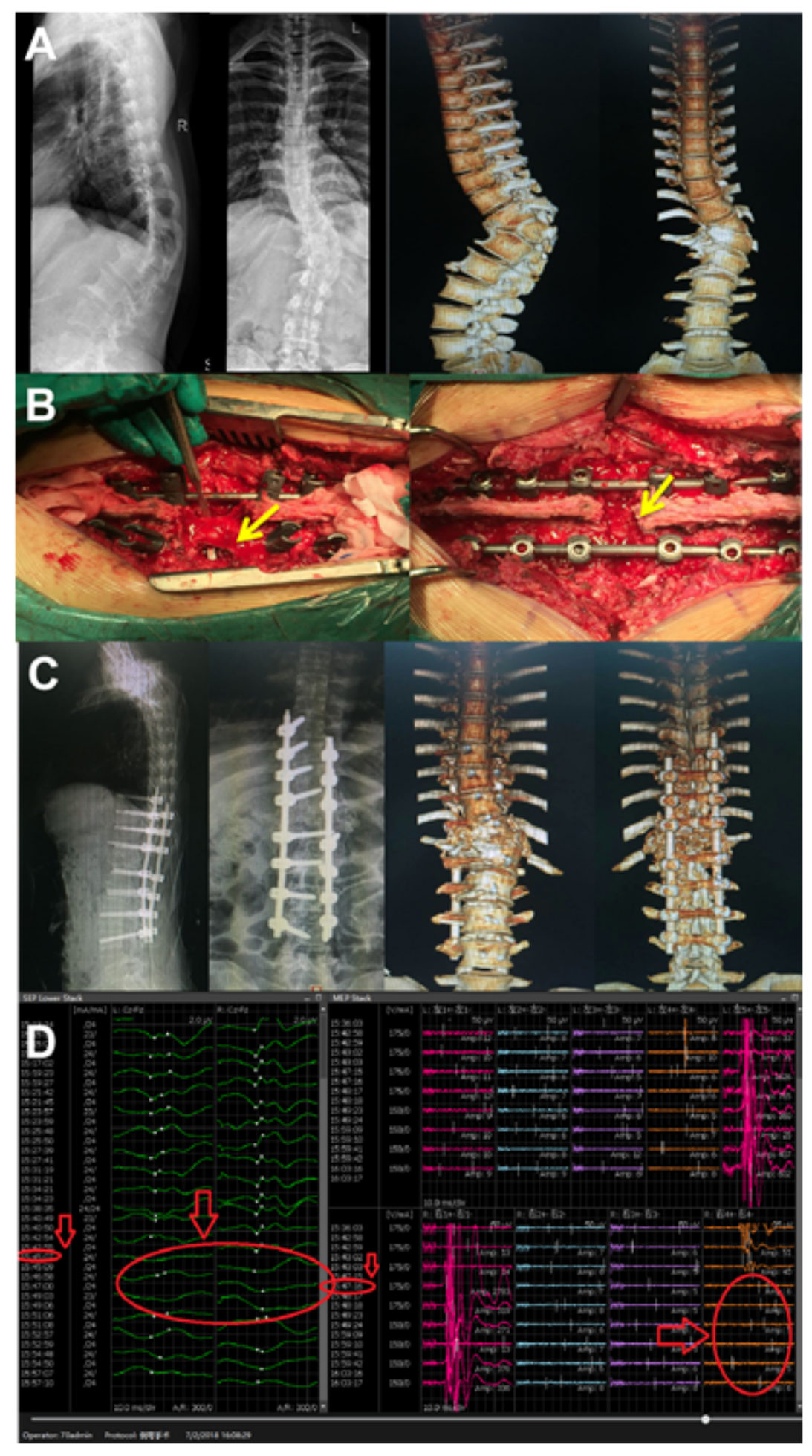

\section{Figure 2}

Case 1, female, 33 years of age, severe rigid thoracolumbar deformity. (A) Preoperative diagnosis was kyphosis Cobb $85^{\circ}$ and scoliosis Cobb $67^{\circ}$ by X-ray after bending and three-dimensional CT imaging. (B) Intraoperative osteotomy, pedicle screw fixation and correction. Yellow arrow represents injury in L1 nerve root on the convex side of scoliosis. (C) Postoperative kyphosis and scoliosis Cobb angle was corrected 
to $12^{\circ}$ and $15^{\circ}$, which show in X-ray and three-dimensional CT imaging. (D) Abnormal waveforms occurred in SEP and MEP of the left lower limb during surgery. Red arrow represents abnormal signal.

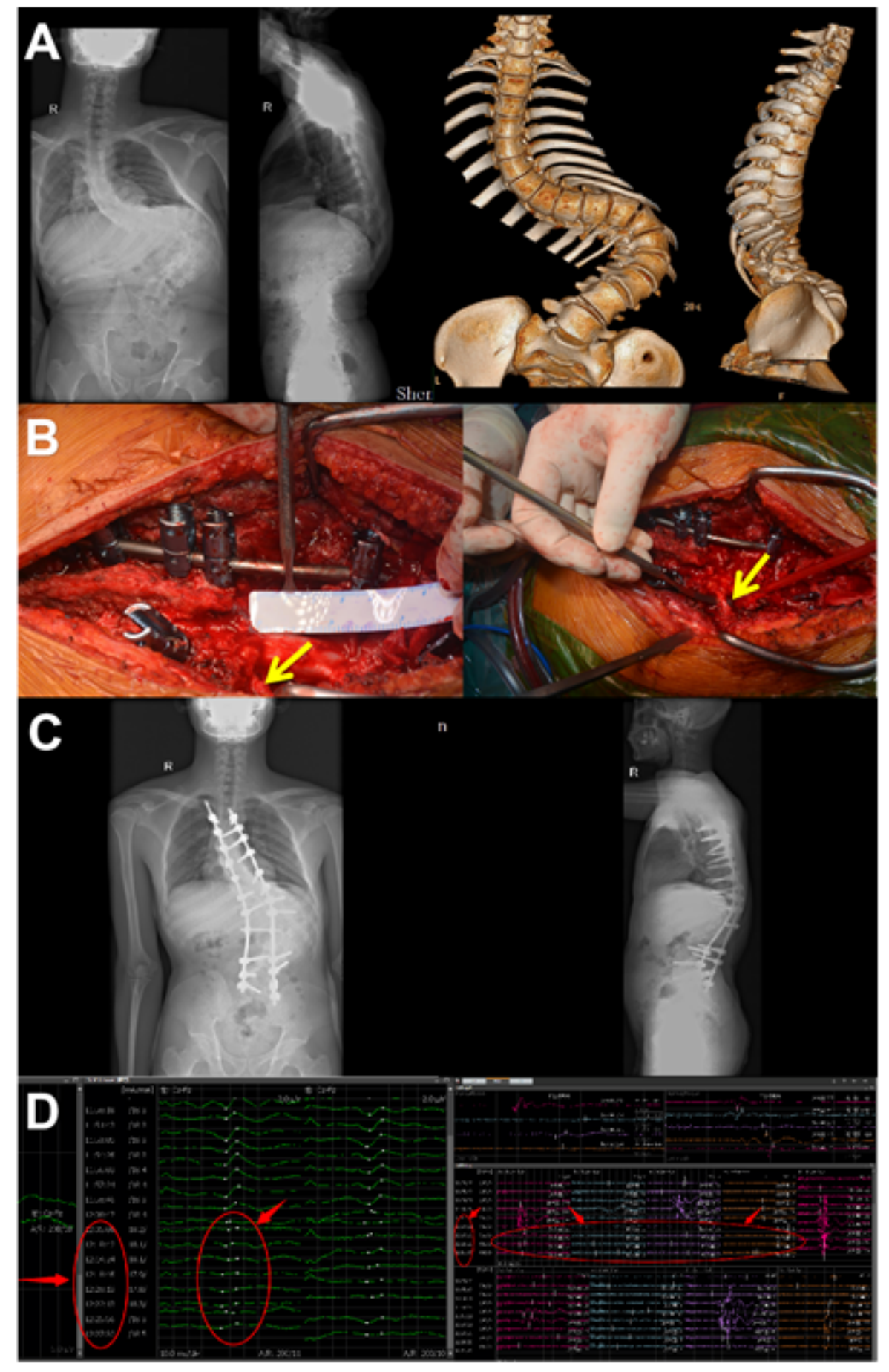

\section{Figure 3}

Case 2, male, 21 years old, severe rigid thoracolumbar deformity. (A) Preoperative diagnosis was kyphosis Cobb $90^{\circ}$ and scoliosis Cobb $130^{\circ}$ by X-ray after bending and three-dimensional CT imaging. (B) Intraoperative osteotomy, pedicle screw fixation and correction. Yellow arrow represents injury in the L1 nerve root on the convex side. (C) Postoperative kyphosis and scoliosis Cobb angle was corrected to $25^{\circ}$ 
and $40^{\circ}$, as shown in X-ray images. (D) Abnormal waveforms occurred in SEP and MEP of the left lower limb during surgery. Red arrow represents abnormal signal.
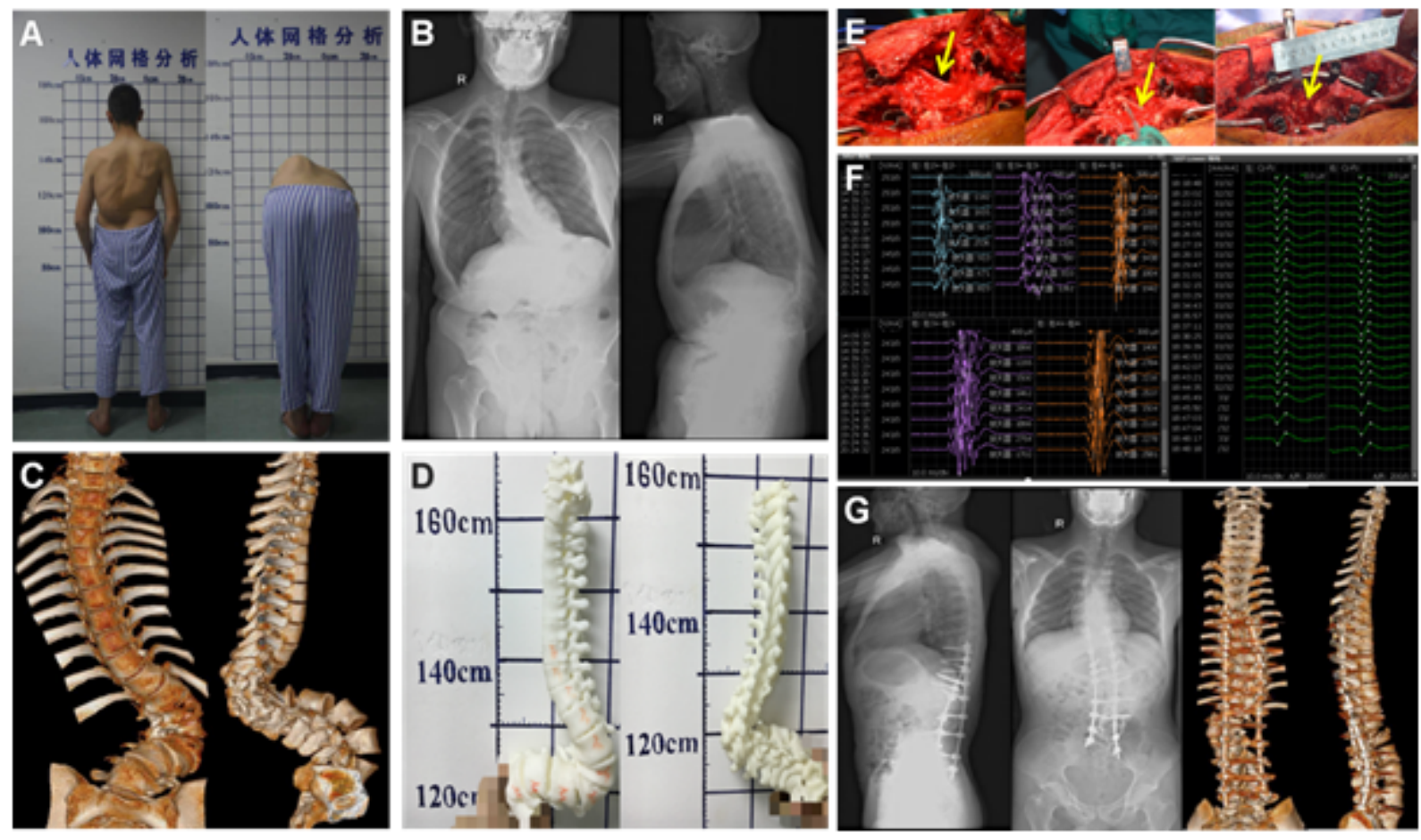

\section{Figure 4}

Case 3, male, 22 years old, severe rigid thoracolumbar deformity. (A, B, C and D) Preoperative diagnosis was kyphosis Cobb angle $102^{\circ}$ and scoliosis Cobb angel $118^{\circ}$ by profile, $\mathrm{X}$-ray after bending, threedimensional CT and printing model imaging. (E) Intraoperative osteotomy, pedicle screws fixation and correction. Yellow arrow represents the intact and slack L1 nerve root. (F) Normal waveforms occurred in SEP and MEP during surgery. (G) Postoperative kyphosis and scoliosis Cobb angle was corrected to $32^{\circ}$ and $35^{\circ}$, as shown in X-ray and three-dimensional CT images.

\section{Supplementary Files}

This is a list of supplementary files associated with this preprint. Click to download.

- ParallelEndplateOsteotomy.mp4 